\title{
Chest CT texture-based radiomics analysis in differentiating COVID-19 from other interstitial pneumonia
}

\author{
Damiano Caruso ${ }^{1}$. Francesco Pucciarelli ${ }^{1} \cdot$ Marta Zerunian ${ }^{1} \cdot$ Balaji Ganeshan ${ }^{2}$ - Domenico De Santis ${ }^{1}$. \\ Michela Polici ${ }^{1}$ - Carlotta Rucci ${ }^{1}$. Tiziano Polidori ${ }^{1}$ - Gisella Guido ${ }^{1}$ - Benedetta Bracci ${ }^{1}$. Antonella Benvenga ${ }^{1}$. \\ Luca Barbato $^{1} \cdot$ Andrea Laghi $^{1}$ (i)
}

Received: 21 April 2021 / Accepted: 12 July 2021 / Published online: 4 August 2021

(c) The Author(s) 2021

\begin{abstract}
Purpose To evaluate the potential role of texture-based radiomics analysis in differentiating Coronavirus Disease-19 (COVID-19) pneumonia from pneumonia of other etiology on Chest CT.

Materials and methods One hundred and twenty consecutive patients admitted to Emergency Department, from March 8, 2020, to April 25, 2020, with suspicious of COVID-19 that underwent Chest CT, were retrospectively analyzed. All patients presented CT findings indicative for interstitial pneumonia. Sixty patients with positive COVID-19 real-time reverse transcription polymerase chain reaction (RT-PCR) and 60 patients with negative COVID-19 RT-PCR were enrolled.

CT texture analysis (CTTA) was manually performed using dedicated software by two radiologists in consensus and textural features on filtered and unfiltered images were extracted as follows: mean intensity, standard deviation (SD), entropy, mean of positive pixels (MPP), skewness, and kurtosis. Nonparametric Mann-Whitney test assessed CTTA ability to differentiate positive from negative COVID-19 patients. Diagnostic criteria were obtained from receiver operating characteristic (ROC) curves.

Results Unfiltered CTTA showed lower values of mean intensity, MPP, and kurtosis in COVID-19 positive patients compared to negative patients ( $p=0.041,0.004$, and 0.002 , respectively). On filtered images, fine and medium texture scales were significant differentiators; fine texture scale being most significant where COVID-19 positive patients had lower SD $(p=0.004)$ and MPP $(p=0.004)$ compared to COVID-19 negative patients. A combination of the significant texture features could identify the patients with positive COVID-19 from negative COVID-19 with a sensitivity of 60\% and specificity of $80 \%(p=0.001)$.
\end{abstract}

Conclusions Preliminary evaluation suggests potential role of CTTA in distinguishing COVID-19 pneumonia from other interstitial pneumonia on Chest CT.

Keywords COVID-19 $\cdot$ Texture analysis $\cdot$ Diagnostic tool $\cdot$ Computed tomography

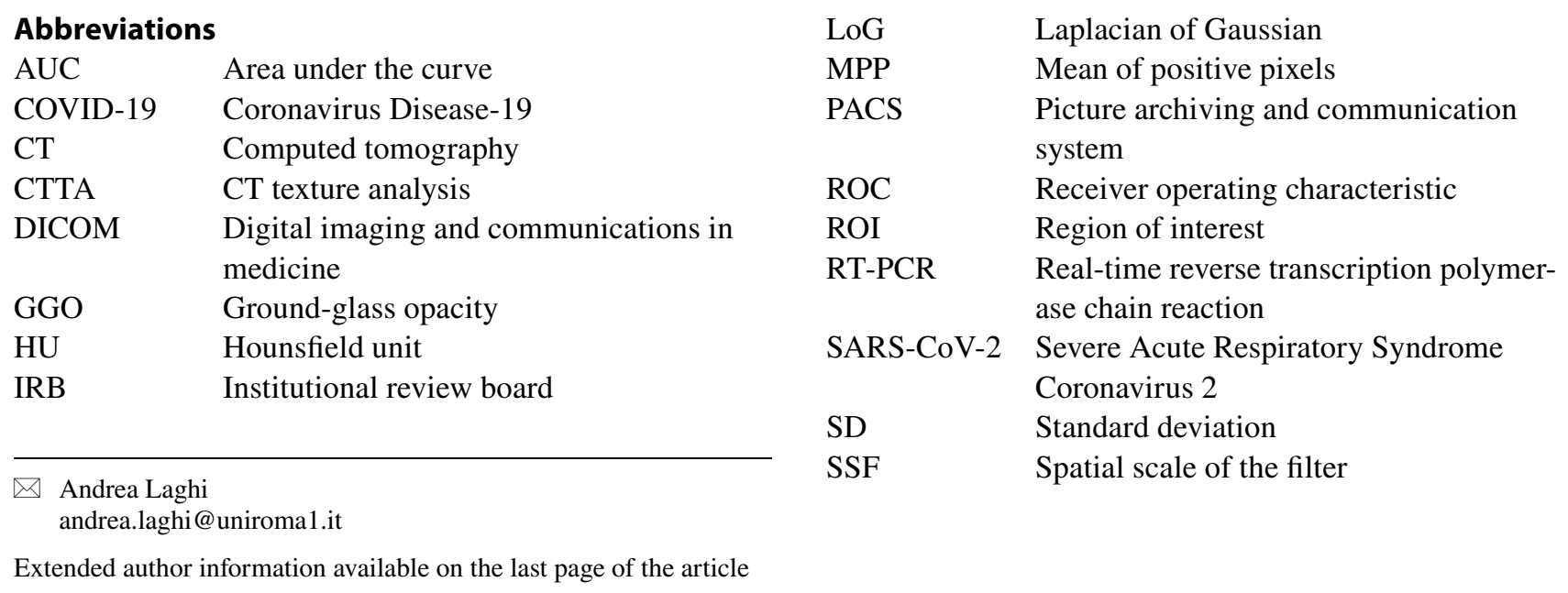




\section{Introduction}

A novel coronavirus, Severe Acute Respiratory Syndrome Coronavirus 2 (SARS-CoV-2) [1], was identified as the causative agent of several clinical conditions, the most common of which is pneumonia, reported as Coronavirus Disease-19 (COVID-19) [2, 3]. On January 2020, WHO declared the Chinese outbreak of COVID-19 to be a public health emergency of international concern.

Factors that could stem COVID-19 spread are: early detection, patients' isolation, prompt treatment, and implementation of a robust system to trace contacts [4]. The reference standard for the diagnosis of SARS-CoV-2 infection is next-generation sequencing or real-time reverse transcription polymerase chain reaction (RT-PCR) methods applied to respiratory tract specimens [5]. However, due to intrinsic limitations of the method (i.e., site of specimen swabs, collection and transportation of samples and diagnostic kit performance), sensitivity of RT-PCR ranges between 63 and $78 \%[6,7]$.

As an adjunct diagnostic tool in suspicious patients, Chest CT has gained an important role in COVID-19 pandemic thanks to its high sensitivity (97\%) in COVID-19 diagnosis $[8,9]$; the most frequent $\mathrm{CT}$ findings are multiple subpleural ground-glass opacities (GGO) associated with crazy paving pattern, consolidations, and small pulmonary vessels enlargement [2]. However, infected patients may show normal CT scans, particularly in the early phase of the disease [10]; moreover, Chest CT showed low specificity $(25-56 \%)$ [11] since other lung infective and noninfective diseases may show similar appearance on Chest CT qualitative assessment [12-14].

Quantitative CT, radiomics, and artificial intelligence software analyses can potentially be effective in assessing severity of disease, increasing CT specificity, and strengthening the role of Chest CT in COVID-19 [15-21]. Among them, CT texture analysis (CTTA) is an emerging area of radiomics that extracts, analyses, and interprets quantitative imaging features not perceivable to the naked human eye.

CTTA allows objective assessment of the distribution of pixel/voxel intensity within a region of interest (ROI), reflecting the underlying biologic heterogeneity related to tissue microenvironment [22-24]. Radiomics machine learning-based tool has been recently studied to evaluate the severity of COVID-19 [25]. A recent study proposed by Wu et al. [26] have shown that despite the similar clinical and radiological manifestations in COVID-19 and non-COVID-19 patients, CT texture features may be a helpful toll to differentiate these two population. As a noninvasive and rapid imaging biomarker, texture analysis could improve COVID-19 chest CT diagnosis reducing false positive with the similar lung imaging pattern and allowing a better management of the disease.

Thus, the aim of our pilot study is to evaluate the potential role of texture-based radiomics analysis in distinguishing COVID-19 interstitial pneumonia from pneumonia of other etiology on Chest CT.

\section{Materials and methods}

\section{Study population}

This study was approved by our local institutional review board (IRB) and written informed consent was waived due to the retrospective nature. From March 8, 2020, to April 25,2020 , individuals with respiratory symptoms (cough and dyspnea) and fever suspected for COVID-19 and admitted to Emergency Department of Sant'Andrea University Hospital of Rome were enrolled and underwent unenhanced Chest CT.

To assess SARS-CoV-2 infection, real-time reverse transcriptase RT-PCR (Charitè, Berlin, Germany) [27] was performed on nasopharyngeal and oropharyngeal swabs collected from individuals on arrival in the Emergency Department and repeated after $24 \mathrm{~h}$. Patients were considered SARS-CoV-2 negative after two consecutive negative RT-PCR results.

For the purpose of the study, inclusion criteria were: (a) availability of RT-PCR results, (b) unenhanced Chest CT performed on arrival, and c) the presence of GGO appreciable on Chest CT. Exclusion criteria were as follows: (a) Chest CT performed with contrast medium injection (e.g., pulmonary embolism suspicion), (b) motion artifacts on Chest $\mathrm{CT}$ and consequent poor image quality unsuitable for CTTA. The study population enrollment flowchart is summarized in Fig. 1.

Epidemiological and laboratory data of enrolled patients were collected.

\section{Chest CT protocol}

All CT exams were performed with a 128 -slice CT scanner (GE Revolution EVO 128 Slice CT Scanner, GE Medical Systems, Milwaukee, WI, USA). Datasets were acquired with patients placed in supine position in full inspiration, applying a standard volumetric protocol for unenhanced Chest CT, with fixed scan parameters (tube voltage: $120 \mathrm{kV}$, tube current modulation: $100-250 \mathrm{mAs}$, spiral pitch factor: 0.98 , collimation width: 0.625 )

Images were reconstructed applying the BONEPLUS convolution kernel, with a slice thickness of $1.25 \mathrm{~mm}$ and a spacing of $1.25 \mathrm{~mm}$. Digital Imaging and Communications in Medicine (DICOM) image data were transferred 
Fig. 1 Patients enrollment flowchart

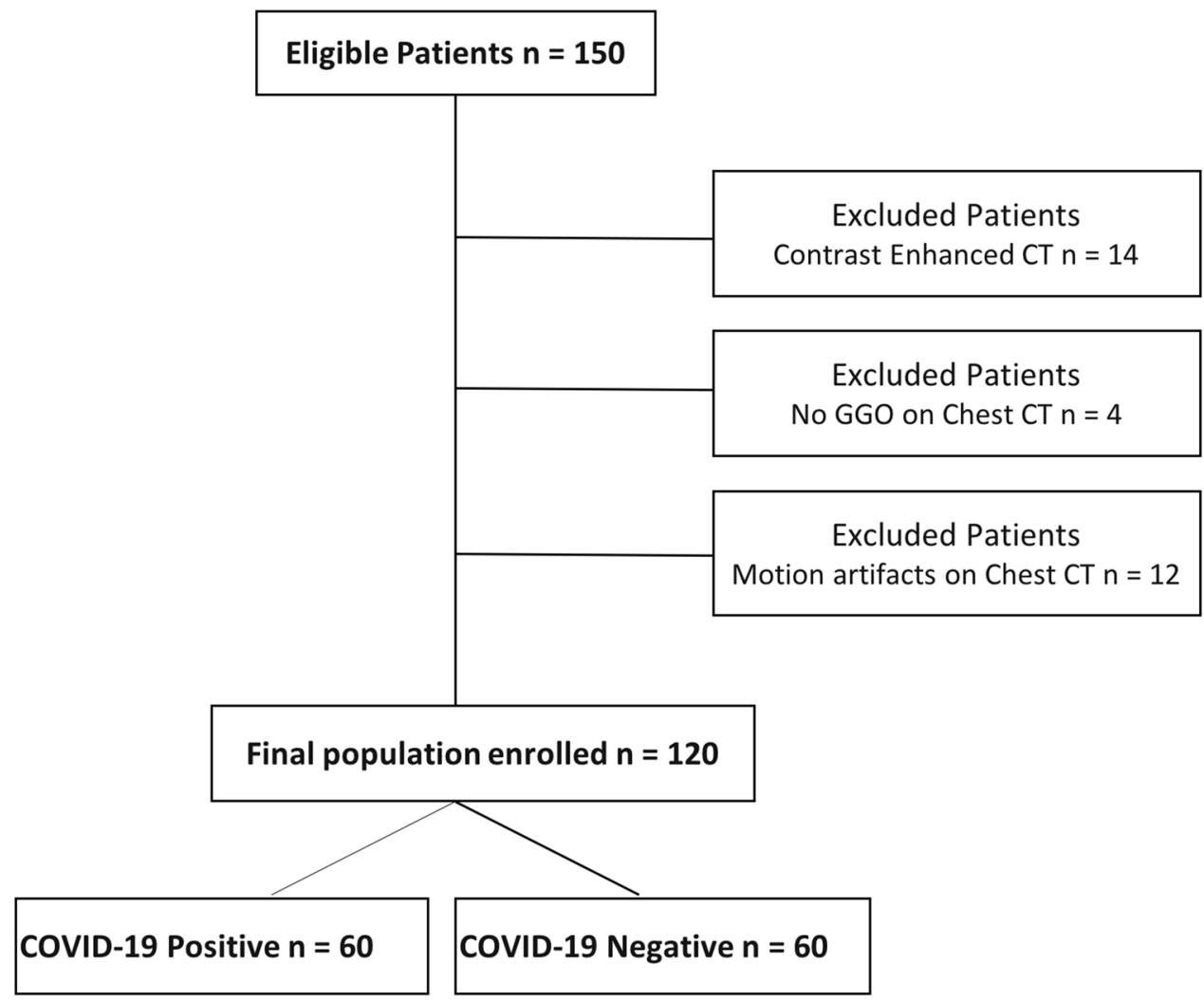

into a picture archiving and communication system (PACS) workstation (Centricity Universal Viewer v.6.0, GE Medical Systems, Milwaukee, WI, USA).

\section{Texture analysis}

DICOM images extracted from PACS were anonymized and transferred to a dedicated texture analysis research software (TexRAD, Feedback Medical Ltd., Cambridge, UK). Two expert radiologists (F.P. and D.C., with 5 and 10 years of experience in thoracic imaging, respectively) performed CTTA on the ROIs, in consensus reading, by encompassing the GGO displayed on the axial Chest CT images with fixed lung window (width: $1500 \mathrm{HU}$; level: $-600 \mathrm{HU})$. ROIs were manually contoured and kept approximately $2 \mathrm{~mm}$ within the margin of the GGO, to exclude from the analysis adjacent structures, such as vessel or bronchial branches, cavities, or normal lung parenchyma (Fig. 2). For each patient, five ROIs were drawn, one for each lung lobe. If GGOs were absent in a lung lobe, remaining ROIs were placed in the most affected lung lobe.

Heterogeneity within each ROI was evaluated using a filtration-histogram-based textural analysis technique. Filtration step using a band-pass Laplacian of Gaussian (LoG) filter comprised of extracting and enhancing image features of different sizes and intensity variation, corresponding to the spatial scale of the filter (SSF in radius).

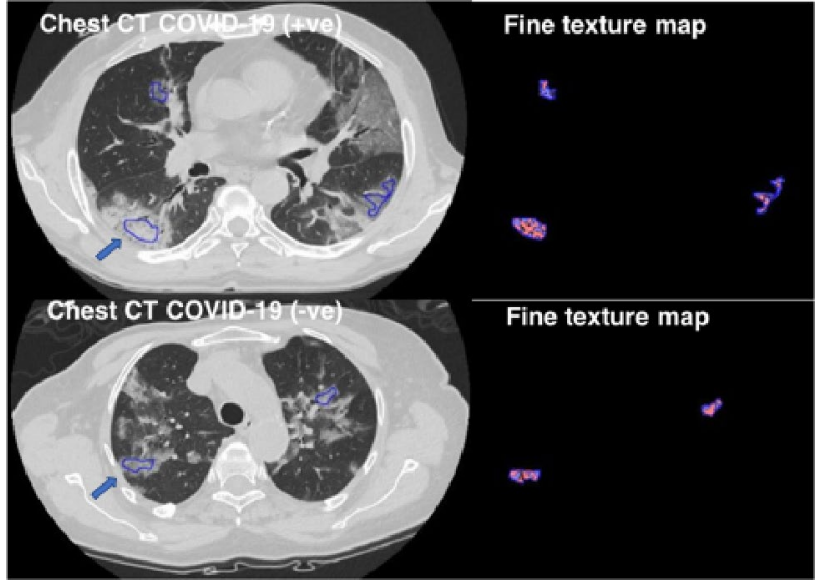

Fig. 2 Workflow demonstrating the process of texture-based radiomics analysis on Chest CT in two patients-one diagnosed as COVID19 positive (above) and other diagnosed as COVID-19 negative (below). ROIs (arrows) were manually contoured and kept approximately $2 \mathrm{~mm}$ within the margin of the GGO, to exclude from the analysis adjacent structures, such as vessel or bronchial branches, cavities, or normal lung parenchyma

The feature scales ranged from $\mathrm{SSF}=2$ to $4 \mathrm{~mm}$, where fine texture scale corresponded to $\mathrm{SSF}=2 \mathrm{~mm}$, medium texture scale corresponded to $\mathrm{SSF}=3 \mathrm{~mm}$, and coarse texture scale corresponded to $\mathrm{SSF}=4 \mathrm{~mm}$. Following the filtration step, texture quantification was computed using 
statistical- and histogram-based parameters at each derived image, as well as on the conventional unfiltered image $(\mathrm{SSF}=0)$.

Statistical and histogram parameters comprised mean intensity, standard deviation (SD), entropy, mean of positive pixels (MPP), kurtosis, and skewness [23]. Figure 2 shows the filtration-histogram-based CTTA of COVID-19 positive and a COVID-19 negative patient.

\section{Statistical analysis}

Patient demographics and clinical parameters were presented as follows: categorical variables as numbers and percentage whereas continuous variables as average and standard deviation. Nonparametric Mann-Whitney test assessed the ability of CTTA parameters and CT density (Hounsfield Unit, HU) to differentiate between the patient groups (positive COVID19 versus negative COVID-19). Box and Whisker plots visualized the difference and trend between the two patient groups for each significant parameter. Diagnostic criteria for a composite score developed by combining the most significant parameters (using the median-value for each parameter from the entire patient population as a cutoff to categorize patients as positive COVID-19 and negative COVID-19) were established using a receiver operating characteristic (ROC) analysis which computed the area under the curve (AUC), cutoff (number of significant predictors), sensitivity, specificity, $p$ value. Statistical analysis was carried out using SPSS (IBM Corp. Released 2017. IBM SPSS Statistics for Macintosh, Version 25.0. Armonk, NY: IBM Corp.) with a $p<0.05$ considered to be significant.

\section{Results}

\section{Study population}

Initial study population comprised 150 patients. However, according to the exclusion criteria, 14 patients were excluded due to a contrast enhanced CT, 4 patients had no lung GGOs, and 12 patients were excluded due to motion artifacts on Chest CT, as shown in the flowchart below (Fig. 1). Therefore, final population consisted of 120 patients with GGO on Chest CT, of which 60 were COVID-19 positive and 60 were COVID-19 negative.

The positive group included 32 males and 28 females with a mean age of $65 \pm 15$ years, while the negative group listed 40 males and 20 females with a mean age of $70 \pm 19$ years, as shown in Table 1.

Among positive COVID-19 patients 41 (68\%) presented dyspnea, 32 (53\%) had cough, and 15 (25\%) showed fever $\left(>37.5^{\circ} \mathrm{C}\right)$. Laboratory blood tests showed typical lymphocytopenia in $49(82 \%)$ patients, high C-reactive protein
Table 1 Clinical parameters and blood test results of positive COVID-19 and negative COVID-19 patients

\begin{tabular}{|c|c|c|c|c|}
\hline \multirow[b]{2}{*}{ Patients demographics } & \multicolumn{2}{|c|}{ COVID-19 positive } & \multicolumn{2}{|c|}{$\begin{array}{l}\text { COVID-19 nega- } \\
\text { tive }\end{array}$} \\
\hline & N. patients & $\%$ & N. patients & $\%$ \\
\hline Mean age & $65 \pm 15 y$ & & $70 \pm 19 y$ & \\
\hline Years (range) & $23-94$ & & $18-98$ & \\
\hline Number patients & 60 & 100 & 60 & 100 \\
\hline Male & $32 / 60$ & 53 & $40 / 60$ & 66 \\
\hline Female & $28 / 60$ & 47 & $20 / 60$ & 34 \\
\hline \multicolumn{5}{|l|}{ Blood test } \\
\hline \multicolumn{5}{|c|}{$C$-reactive protein ( $\mathrm{mg} / \mathrm{L}$; normal range $0.00-0.50)$} \\
\hline Increased & $58 / 60$ & 97 & $54 / 60$ & 90 \\
\hline Normal & $2 / 60$ & 3 & $6 / 60$ & 10 \\
\hline \multicolumn{5}{|c|}{ Lactic acid dehydrogenase (U/L; range 125-220) } \\
\hline Increased & $56 / 60$ & 93 & $49 / 60$ & 82 \\
\hline Normal & $4 / 60$ & 7 & $11 / 60$ & 18 \\
\hline \multicolumn{5}{|c|}{ Lymphocytes $\left(\times 10^{3} / \mathrm{mm}^{3}\right.$, normal range $\left.1.5-3.0\right)$} \\
\hline Increased & $1 / 60$ & 1 & $2 / 60$ & 3 \\
\hline Decreased & $49 / 60$ & 82 & $40 / 60$ & 67 \\
\hline Normal & $10 / 60$ & 17 & $18 / 60$ & 30 \\
\hline \multicolumn{5}{|c|}{ D-dimer $(\mathrm{ng} / \mathrm{ml}$, normal<243) } \\
\hline Increased & $40 / 60$ & 67 & $48 / 60$ & 80 \\
\hline Normal & $20 / 60$ & 33 & $12 / 60$ & 20 \\
\hline \multicolumn{5}{|l|}{ Symptoms } \\
\hline Fever $\left(>37.5^{\circ}\right)$ & $15 / 60$ & 25 & $11 / 60$ & 18 \\
\hline Cough & $32 / 60$ & 53 & $36 / 60$ & 60 \\
\hline Dyspnea & $41 / 60$ & 68 & $31 / 60$ & 52 \\
\hline
\end{tabular}

$(>0.50 \mathrm{mg} / \mathrm{dL})$ in $58(97 \%)$, rise of lactate dehydrogenase $(>220 \mathrm{U} / \mathrm{L})$, and D-dimer (>243 $\mathrm{ng} / \mathrm{ml})$ in $56(93 \%)$ and 40 (67\%) patients, respectively.

Among negative COVID-19 patients 36 (60\%) had cough, 31 (52\%) presented dyspnea, and 11 (18\%) had fever. C-reactive protein, lactate dehydrogenase and D-dimer were above the threshold values in 54 (90\%), 49 (82\%), and 48 (80\%) patients, respectively. Lymphocytopenia was found in $40(67 \%)$ patients. The complete results are listed in Table 1.

\section{Image analysis}

On unfiltered images, COVID-19 positive patients had a lower mean intensity ( $-289 \mathrm{HU}$ vs. $-247 \mathrm{HU} ; p=0.041)$, MPP (25.3 vs. $35.3 ; p=0.004)$, and kurtosis (0.2 vs. 0.6; $p=0.002$ ) compared to negative COVID-19 individuals (Fig. 3).

On fine texture scale, COVID-19 positive patients had a lower SD (287.9 vs. 322.2; $p=0.004)$ and MPP (271.7 vs. $309.5 ; p=0.004)$. The comparable results have been obtained on medium texture scale, in which COVID-19 positive patients accounted for lower SD (275.7 vs. 312.6; 

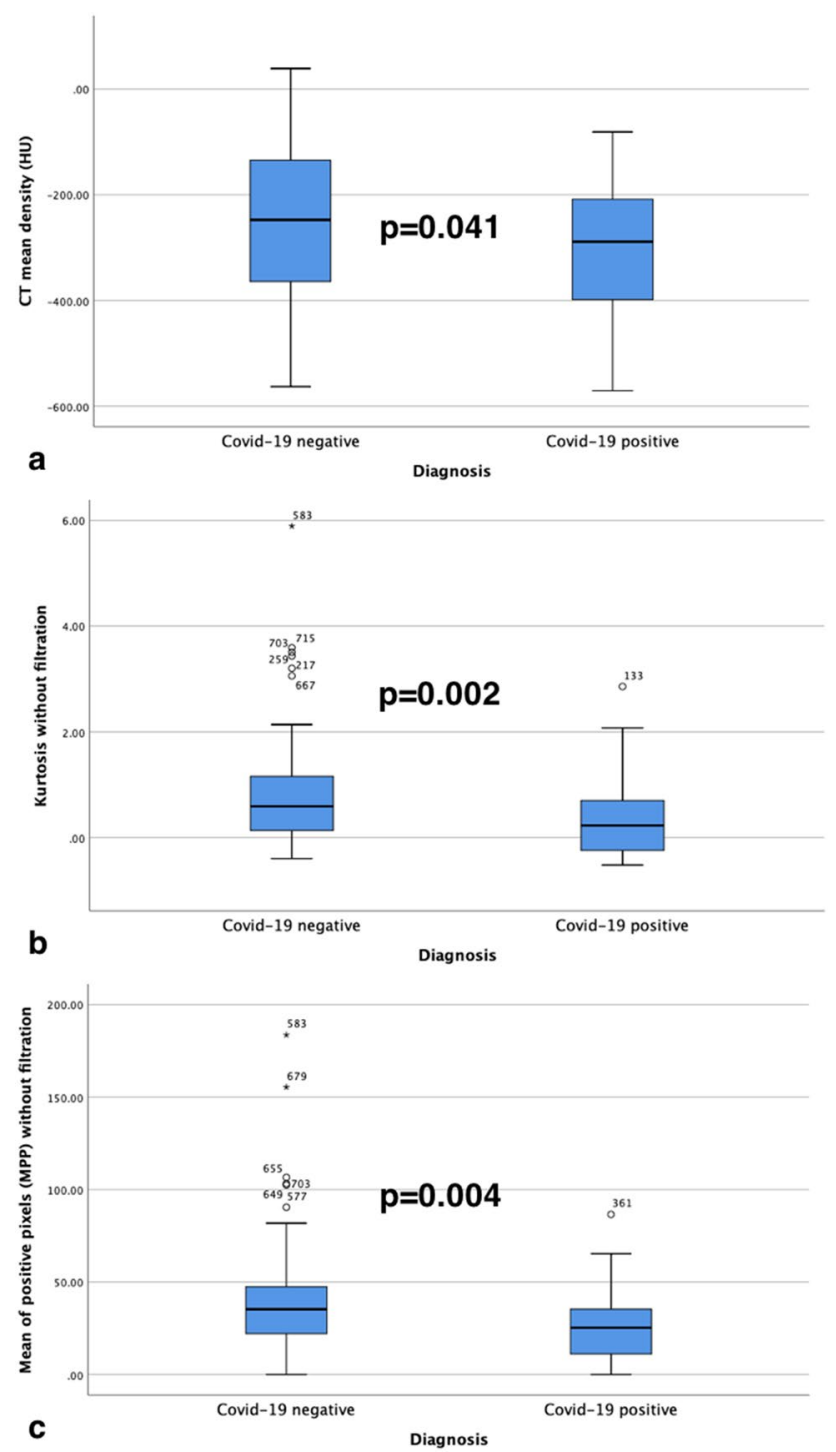

Fig. 3 Box and Whisker plots highlight the significant difference between Mean CT density (a), texture parameters Kurtosis (b) and Mean of Positive Pixels (MPP) (c) without filtration for COVID-19 diagnosis

$p=0.012)$ and MPP (272.0 vs. $324.2 ; p=0.023)$ compared to negative COVID-19 patients (Fig. 4). Coarse texture scale provided no significant differences in texture parameters between the two groups. The comprehensive results are summarized in Table 2.

A composite score developed by combining the most significant differentiators (fine texture scale: MPP $<290.122$ and $\mathrm{SD}<306.547$; unfiltered images: $\mathrm{MPP}<27.576$ and kurtosis $<0.356)$ could differentiate COVID-19 positive patients from negative patients $(p<0.001)$. Specifically, the presence of any three or more of the above risk factors could identify COVID-19 positive patients from negative patients with a sensitivity of $60 \%$ and specificity of $80 \%$ (AUC $=0.7$, $p<0.001$; Fig. 5).

\section{Discussion}

This pilot study showed the ability of CTTA to differentiate between COVID-19 positive and negative patients. SD and MPP at fine and medium filter scales had significantly lower values in positive COVID-19 patients compared to subject with interstitial pneumonia of other etiology, particularly at fine texture scale. Additionally, both kurtosis and MPP were lower in positive COVID-19 patients in the unfiltered image dataset. Such results, along with lower CT density in positive COVID-19 subjects, potentially reflects variation in $\mathrm{GGO} /$ parenchymal heterogeneity between the two groups. A combined score including the most significant texture parameters (presence of three or more risk factors) showed a good diagnostic performance in the identification of COVID-19 positive patients.

The last decade has seen a rapid growth of CTTA, especially applied in oncologic imaging, aiming to assess solid tumors' heterogeneity and aggressiveness [28-34]. In thoracic oncology, CTTA has demonstrated the feasibility in predicting survival [35] and response to anti-angiogenic chemotherapy and immunotherapy [36-38] in lung cancer, in distinguishing lung cancer recurrence from postradiation fibrosis [39], and the ability to assess pulmonary sub-nodules aggressiveness [40].

CTTA has been also applied in diffuse lung disease, such as pulmonary emphysema, pulmonary idiopathic fibrosis, and pulmonary embolism [41, 42]. Particularly, CTTA of pulmonary angiograms has been proved effective in providing correlates for ventilated and vascular lung, similar to a ventilation-perfusion V/Q scan, aiding in the diagnosis of pulmonary embolism in the presence of other causes of altered vascularity such as emphysema [42]. Other studies have explored the feasibility of CTTA to differentiate diffuse pulmonary alterations that appears very similar on visual assessment. Kloth et al. proved CTTA able to differentiate active alveolitis and lung fibrosis in patients with systemic sclerosis [43], as well alveolar hemorrhage from Pneumocystis jirovecii pneumonia [44], overcoming diagnostic challenges present on mere visual assessment due to overlapping imaging findings between the two entities at early stages. Therefore, CTTA might play a significant role in early differentiation of various pulmonary conditions manifesting with GGO, requiring different treatments and optimizes patient management.

Another investigation [45] applied CTTA in the identification of pulmonary abnormalities caused by H1N1 influenza on Chest CT, demonstrating that mean intensity, SD, and non-uniformity could differentiate between abnormal 

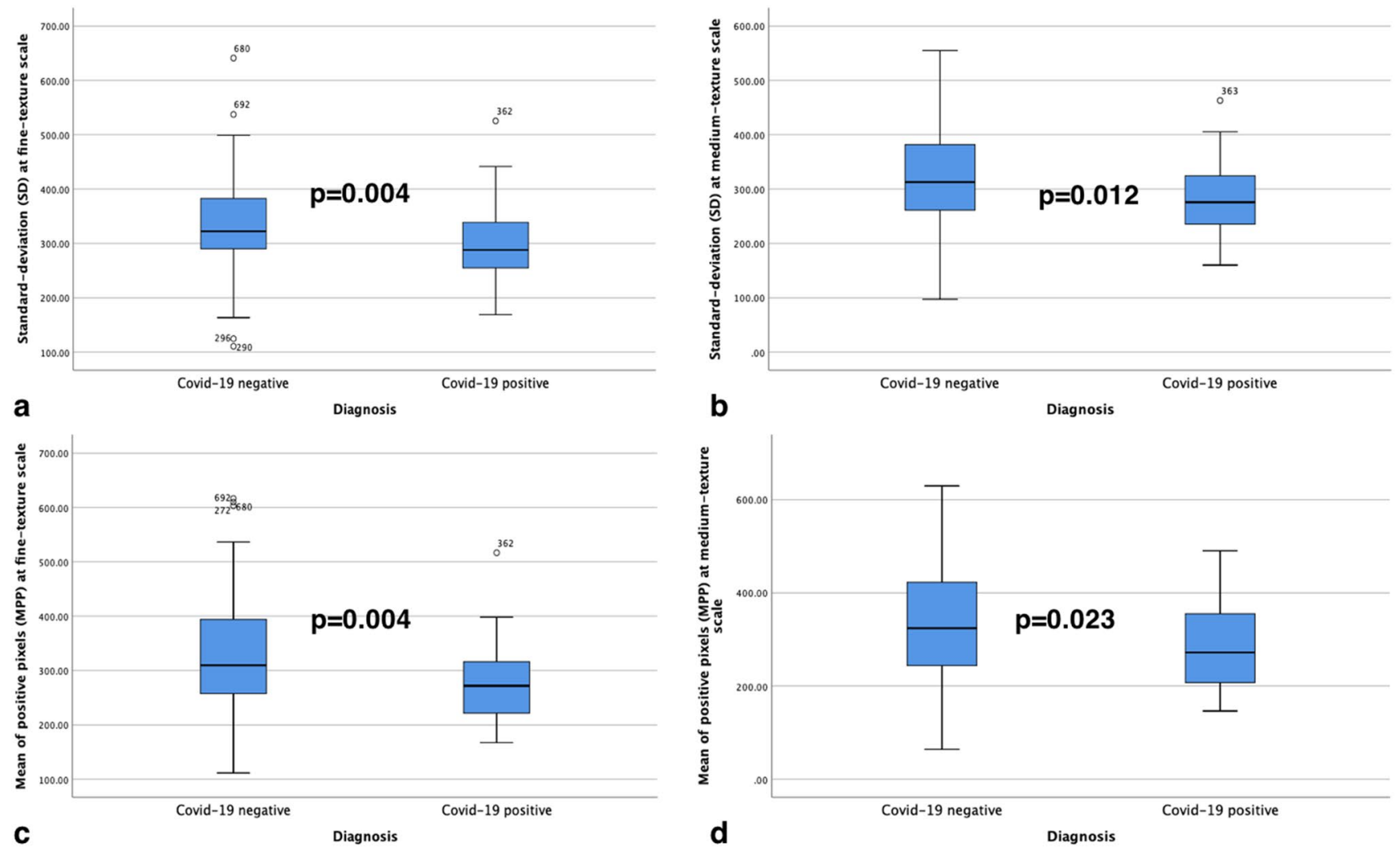

Fig. 4 Box and Whisker plots highlight the significant differences at fine and medium texture parameters in terms of Standard Deviation (SD) (a and $\mathbf{b})$ and Mean of Positive Pixels (MPP) (c and d) for COVID-19 diagnosis

regions on $\mathrm{H} 1 \mathrm{~N} 1$ influenza patients from pulmonary fibrosis, normal and non-influenza infections. In accordance with previous investigation, in our study key differentiators were texture metrics (MPP, SD, and kurtosis) without and with filtration (fine and medium texture scales). These CTTA metrics reflect heterogeneity (intensity variation, irregularity, and tissue-contrast) in the distribution of parenchymal attenuation. Above studies demonstrate how CTTA extracts subtle image characteristic not perceivable to the naked eye and might aid radiologists in their diagnostic tasks.

As demonstrated by Wu et al. [26] CTTA could be used to rapidly differentiate COVID-19 from other infectious pneumonia. However, radiomic signature has been proven effective in classifying between stable and progressive group of COVID-19 patients with an AUC, sensitivity and specificity of $0.8,81$, and $74 \%$, respectively [25]. Our study highlights the feasibility of CTTA in the COVID-19 patient management, with a performance higher than the mere visual assessment. CTTA is readily applicable as an adjunct tool in a routine clinical setting whether the preliminary results from our pilot study could be confirmed on larger scale. Our results may potentially reflect histopathological differences in parenchymal findings; the different inflammatory infiltrate induced by the SARS-CoV could explain the differences on CTTA in patients with COVID-19 disease compared to those with same CT findings related to the other interstitial pneumonia, as demonstrated by the lower CT density in positive COVID-19 subjects.

The implementation of CTTA might strengthen the role of Chest CT during COVID-19 pandemic, potentially improving patient management in the emergency department [45].

Despite the encouraging results, the study has limitations related to its retrospective nature, its single-center design, the small sample size and the lack of inter-reader agreement due to in consensus reading. Nevertheless, previous studies have demonstrated good reproducibility for filtration-histogram-based CTTA using multicenter clinical validation [35, 46] and robustness to variation in image acquisition parameters $[47,48]$. It is worth noting that the contour of the GGO was drawn on a single axial slice. Although the multi-slice or volume delineation of GGO would be a better representation within the whole lung, such methodology is time-consuming and therefore not practical in clinical setting. Furthermore, 
Table 2 Summary of results (median) for Chest CT texture parameters within the two patient diagnostic groups

\begin{tabular}{|c|c|c|c|}
\hline CT texture parameters & $\begin{array}{l}\text { COVID- } \\
19 \text { positive } \\
\text { (median) }\end{array}$ & $\begin{array}{l}\text { COVID-19 } \\
\text { negative } \\
\text { (median) }\end{array}$ & $p$ value \\
\hline \multicolumn{4}{|c|}{ Without filtration-SSF $=0$} \\
\hline Mean intensity (HU) & -288.710 & -247.353 & 0.041 \\
\hline Standard deviation & 111.783 & 125.147 & 0.052 \\
\hline Entropy & 4.733 & 4.758 & 0.954 \\
\hline Mean of positive pixels & 25.313 & 35.302 & 0.004 \\
\hline Skewness & -0.059 & -0.055 & 0.324 \\
\hline Kurtosis & 0.227 & 0.590 & 0.002 \\
\hline \multicolumn{4}{|c|}{ Fine texture scale-SSF $=2$} \\
\hline Mean intensity & 44.009 & 86.771 & 0.114 \\
\hline Standard deviation & 287.950 & 322.172 & 0.004 \\
\hline Entropy & 4.869 & 4.928 & 0.618 \\
\hline Mean of positive pixels & 271.700 & 309.479 & 0.004 \\
\hline Skewness & 0.027 & 0.075 & 0.713 \\
\hline Kurtosis & 0.202 & 0.131 & 0.797 \\
\hline \multicolumn{4}{|c|}{ Medium texture scale $-S S F=3$} \\
\hline Mean intensity & 81.300 & 119.381 & 0.155 \\
\hline Standard deviation & 275.755 & 312.614 & 0.012 \\
\hline Entropy & 4.857 & 4.918 & 0.609 \\
\hline Mean of positive pixels & 272.036 & 324.228 & 0.023 \\
\hline Skewness & -0.045 & -0.050 & 0.834 \\
\hline Kurtosis & -0.150 & -0.071 & 0.648 \\
\hline \multicolumn{4}{|c|}{ Coarse texture scale $-S S F=4$} \\
\hline Mean intensity & 69.778 & 123.457 & 0.174 \\
\hline Standard deviation & 255.785 & 284.804 & 0.091 \\
\hline Entropy & 4.834 & 4.934 & 0.513 \\
\hline Mean of positive pixels & 258.064 & 306.420 & 0.108 \\
\hline Skewness & -0.138 & -0.148 & 0.867 \\
\hline Kurtosis & -0.289 & -0.285 & 0.871 \\
\hline
\end{tabular}

Statistically significant results based on Mann-Whitney test are highlighted in bold

the comparable results in heterogeneity assessment have been reported between cross-sectional area and whole volume analysis on CT [49]. Lastly, the absence of histopathologic correlation did not allow for confirmation of the above hypothesis between the significant CTTA parameters and the tissue/parenchymal alterations caused by SARS-CoV-2 and immune system response.

In conclusion, CTTA parameters with and without filtration such as SD, MPP, and kurtosis can help to differentiate between positive and negative COVID-19 patients with higher specificity than simple visual assessment and could potentially be used as an adjunct tool during radiological interpretation of Chest CT.

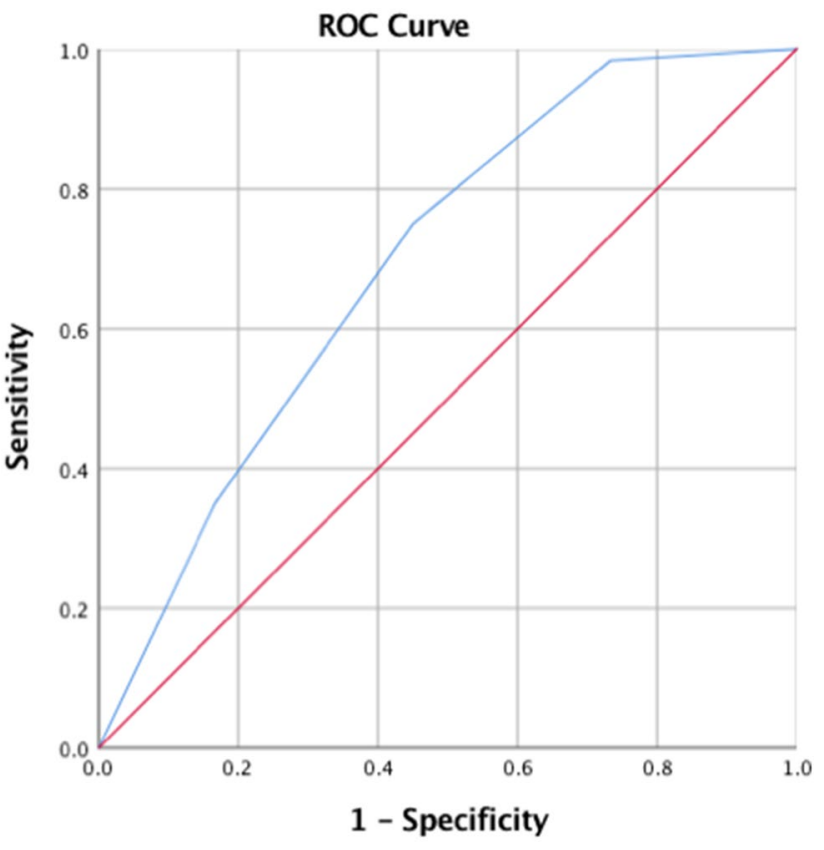

Fig. 5 ROC analysis for the composite score was developed by combining the most significant texture parameters [fine texture: Mean of Positive Pixels (MPP) and Standard Deviation; without filtration texture: MPP and Kurtosis]. The presence of three or more risk factors identified patients with positive COVID-19 from patients with negative COVID-19 with a sensitivity of $60 \%$ and specificity of $80 \%$ $(\mathrm{AUC}=0.7, p<0.001)$

Funding Open access funding provided by Università degli Studi di Roma La Sapienza within the CRUI-CARE Agreement. None.

Availability of data and material The datasets during and/or analyzed during the current study available from the corresponding author on reasonable request.

Code availability Texture analysis was performed by using a dedicated software (TexRAD, Feedback Medical Ltd., Cambridge, UK).

\section{Declarations}

Conflict of interest The authors declare that they have no conflict of interest.

Consent for publication The authors affirm that human research participants provided informed consent for publication of the images in Fig. 2.

Ethical Approval This retrospective study was approved by our local institutional review board (IRB) and written informed consent was obtained from all patients or in case of inability from their relatives or the admitting physicians.

Ethical statement This article does not contain any studies with human participants or animals performed by any of the authors.

Consent to participate Informed consent was obtained from all individual participants included in the study. 
Open Access This article is licensed under a Creative Commons Attribution 4.0 International License, which permits use, sharing, adaptation, distribution and reproduction in any medium or format, as long as you give appropriate credit to the original author(s) and the source, provide a link to the Creative Commons licence, and indicate if changes were made. The images or other third party material in this article are included in the article's Creative Commons licence, unless indicated otherwise in a credit line to the material. If material is not included in the article's Creative Commons licence and your intended use is not permitted by statutory regulation or exceeds the permitted use, you will need to obtain permission directly from the copyright holder. To view a copy of this licence, visit http://creativecommons.org/licenses/by/4.0/.

\section{References}

1. Coppola F, Faggioni L, Neri E, Grassi R, Miele V (2021) Impact of the COVID-19 outbreak on the profession and psychological wellbeing of radiologists: a nationwide online survey. Insights Imaging 12(1):23. https://doi.org/10.1186/s13244-021-00962-2

2. Caruso D, Zerunian M, Polici M, Pucciarelli F, Polidori T, Rucci C, Guido G, Bracci B, De Dominicis C, Laghi A (2020) Chest CT features of COVID-19 in Rome. Italy Radiol 296(2):E79-e85. https://doi.org/10.1148/radiol.2020201237

3. Caruso D, Zerunian M, Pucciarelli F, Lucertini E, Bracci B, Polidori T, Guido G, Polici M, Rucci C, Iannicelli E, Laghi A (2021) Imaging of abdominal complications of COVID-19 infection. BJRIOpen 2:20200052

4. Helmy YA, Fawzy M, Elaswad A, Sobieh A, Kenney SP, Shehata AA (2020) The COVID-19 pandemic: a comprehensive review of taxonomy, genetics, epidemiology, diagnosis, treatment, and control. J Clin Med. https://doi.org/10.3390/jcm9041225

5. Organization WH (2020) Laboratory testing for 2019 novel coronavirus (2019-nCoV) in suspected human cases. https://www. who.int/publications/i/item/10665-331501

6. Zitek T (2020) The appropriate use of testing for COVID-19. West J Emerg Med 21(3):470-472. https://doi.org/10.5811/westj em.2020.4.47370

7. Reginelli A, Grassi R, Feragalli B, Belfiore MP, Montanelli A, Patelli G, La Porta M, Urraro F, Fusco R, Granata V, Petrillo A, Giacobbe G, Russo GM, Sacco P, Cappabianca S (2021) Coronavirus isease 2019 (COVID-19) in Italy: double reading of chest CT examination. Biology (Basel) https://doi.org/10.3390/biolo gy10020089

8. Ai T, Yang Z, Hou H, Zhan C, Chen C, Lv W, Tao Q, Sun Z, Xia L (2020) Correlation of chest CT and RT-PCR testing for coronavirus disease 2019 (COVID-19) in China: a report of 1014 cases. Radiology 296(2):E32-E40. https://doi.org/10.1148/radiol.20202 00642

9. Caruso D, Polidori T, Guido G, Nicolai M, Bracci B, Cremona A, Zerunian M, Polici M, Pucciarelli F, Rucci C, Dominicis C, Girolamo MD, Argento G, Sergi D, Laghi A (2020) Typical and atypical COVID-19 computed tomography findings. World J Clin Cases 8(15):3177-3187. https://doi.org/10.12998/wjcc.v8.i15. 3177

10. Kanne JP, Little BP, Chung JH, Elicker BM, Ketai LH (2020) Essentials for radiologists on COVID-19: an update-. Radiology 296(2):E113-E114. https://doi.org/10.1148/radiol.2020200527

11. Kim H, Hong H, Yoon SH (2020) Diagnostic performance of CT and reverse transcriptase polymerase chain reaction for coronavirus disease 2019: a meta-analysis. Radiology 296(3):E145-E155. https://doi.org/10.1148/radiol.2020201343

12. Frazier AA, Franks TJ, Cooke EO, Mohammed TL, Pugatch RD, Galvin JR (2008) From the archives of the AFIP: pulmonary alveolar proteinosis. Radiographics 28(3): 883-899 https://doi. org/10.1148/rg.283075219

13. Moon JH, Kim EA, Lee KS, Kim TS, Jung KJ, Song JH (2000) Cytomegalovirus pneumonia: high-resolution CT findings in ten non-AIDS immunocompromised patients. Korean J Radiol 1(2):73-78. https://doi.org/10.3348/kjr.2000.1.2.73

14. Ellis SJ, Cleverley JR, Müller NL (2000) Drug-induced lung disease: high-resolution CT findings. AJR Am J Roentgenol 175(4):1019-1024. https://doi.org/10.2214/ajr.175.4.1751019

15. Caruso D, Polici M, Zerunian M, Pucciarelli F, Polidori T, Guido G, Rucci C, Bracci B, Muscogiuri E, De Dominicis C, Laghi A (2020) Quantitative Chest CT analysis in discriminating COVID19 from non-COVID-19 patients. Radiol Med (Torino). https:// doi.org/10.1007/s11547-020-01291-y

16. Alimadadi A, Aryal S, Manandhar I, Munroe PB, Joe B, Cheng X (2020) Artificial intelligence and machine learning to fight COVID-19. Physiol Genomics 52(4):200-202. https://doi.org/ 10.1152/physiolgenomics.00029.2020

17. Li L, Qin L, Xu Z, Yin Y, Wang X, Kong B, Bai J, Lu Y, Fang Z, Song Q, Cao K, Liu D, Wang G, Xu Q, Fang X, Zhang S, Xia J, Xia J (2020) Using artificial intelligence to detect COVID-19 and community-acquired pneumonia based on pulmonary CT: evaluation of the diagnostic accuracy. Radiology 296(2):E65-e71. https://doi.org/10.1148/radiol.2020200905

18. Watanabe M, Caruso D, Tuccinardi D, Risi R, Zerunian M, Polici M, Pucciarelli F, Tarallo M, Strigari L, Manfrini S, Mariani S, Basciani S, Lubrano C, Laghi A, Gnessi L (2020) Visceral fat shows the strongest association with the need of intensive care in patients with COVID-19. Metabolism 111:154319. https://doi. org/10.1016/j.metabol.2020.154319

19. Grassi R, Belfiore MP, Montanelli A, Patelli G, Urraro F, Giacobbe G, Fusco R, Granata V, Petrillo A, Sacco P, Mazzei MA, Feragalli B, Reginelli A, Cappabianca S (2021) COVID-19 pneumonia: computer-aided quantification of healthy lung parenchyma, emphysema, ground glass and consolidation on chest computed tomography (CT). Radiol Med 126(4):553-560. https://doi.org/ 10.1007/s11547-020-01305-9

20. Belfiore MP, Urraro F, Grassi R, Giacobbe G, Patelli G, Cappabianca S, Reginelli A (2020) Artificial intelligence to codify lung CT in Covid-19 patients. Radiol Med 125(5):500-504. https://doi. org/10.1007/s11547-020-01195-x

21. Neri E, Miele V, Coppola F, Grassi R (2020) Use of CT and artificial intelligence in suspected or COVID-19 positive patients: statement of the Italian Society of Medical and Interventional Radiology. Radiol Med 125(5):505-508. https://doi.org/10.1007/ s11547-020-01197-9

22. Lubner MG, Smith AD, Sandrasegaran K, Sahani DV, Pickhardt PJ (2017) CT texture analysis: definitions, applications, biologic correlates, and challenges. Radiographics 37(5):1483-1503. https://doi.org/10.1148/rg.2017170056

23. Miles KA, Ganeshan B, Hayball MP (2013) CT texture analysis using the filtration-histogram method: what do the measurements mean? Cancer Imaging 13(3):400-406. https://doi.org/10.1102/ 1470-7330.2013.9045

24. Soomro MH, Giunta G, Laghi A, Caruso D, Ciolina M, Marchis CD, Conforto S, Schmid M (2020) Haralick's texture analysis applied to colorectal T2-weighted MRI: a preliminary study of significance for cancer evolution. In: Biomedical engineering, 2017/03/02 2017. ACTA Press. https://doi.org/10.2316/P.2016. 852-019

25. Fu L, Li Y, Cheng A, Pang P, Shu Z (2020) A novel machine learning-derived radiomic signature of the whole lung differentiates stable from progressive COVID-19 infection: a retrospective cohort study. J Thorac Imaging. https://doi.org/10.1097/RTI. 0000000000000544 
26. Wu Z, Li L, Jin R, Liang L, Hu Z, Tao L, Han Y, Feng W, Zhou D, Li W, Lu Q, Liu W, Fang L, Huang J, Gu Y, Li H, Guo X (2021) Texture feature-based machine learning classifier could assist in the diagnosis of COVID-19. Eur J Radiol 137:109602. https://doi. org/10.1016/j.ejrad.2021.109602

27. Corman VM, Landt O, Kaiser M, Molenkamp R, Meijer A, Chu DK, Bleicker T, Brunink S, Schneider J, Schmidt ML, Mulders DG, Haagmans BL, van der Veer B, van den Brink S, Wijsman L, Goderski G, Romette JL, Ellis J, Zambon M, Peiris M, Goossens H, Reusken C, Koopmans MP, Drosten C (2020) Detection of 2019 novel coronavirus (2019-nCoV) by real-time RT-PCR. Eurosurveillance. https://doi.org/10.2807/1560-7917.ES.2020. 25.3.2000045

28. Ahn SY, Park CM, Park SJ, Kim HJ, Song C, Lee SM, McAdams HP, Goo JM (2015) Prognostic value of computed tomography texture features in non-small cell lung cancers treated with definitive concomitant chemoradiotherapy. Invest Radiol 50(10):719725. https://doi.org/10.1097/RLI.0000000000000174

29. Brenet Defour L, Mule S, Tenenhaus A, Piardi T, Sommacale D, Hoeffel C, Thiefin G (2019) Hepatocellular carcinoma: CT texture analysis as a predictor of survival after surgical resection. Eur Radiol 29(3):1231-1239. https://doi.org/10.1007/ s00330-018-5679-5

30. Ganeshan B, Abaleke S, Young RC, Chatwin CR, Miles KA (2010) Texture analysis of non-small cell lung cancer on unenhanced computed tomography: initial evidence for a relationship with tumour glucose metabolism and stage. Cancer Imaging 10:137-143. https://doi.org/10.1102/1470-7330.2010.0021

31. Ganeshan B, Panayiotou E, Burnand K, Dizdarevic S, Miles $\mathrm{K}$ (2012) Tumour heterogeneity in non-small cell lung carcinoma assessed by CT texture analysis: a potential marker of survival. Eur Radiol 22(4):796-802. https://doi.org/10.1007/ s00330-011-2319-8

32. Ng F, Ganeshan B, Kozarski R, Miles KA, Goh V (2013) Assessment of primary colorectal cancer heterogeneity by using wholetumor texture analysis: contrast-enhanced CT texture as a biomarker of 5-year survival. Radiology 266(1):177-184. https://doi. org/10.1148/radiol.12120254

33. Hayano K, Tian F, Kambadakone AR, Yoon SS, Duda DG, Ganeshan B, Sahani DV (2015) Texture analysis of non-contrastenhanced computed tomography for assessing angiogenesis and survival of soft tissue sarcoma. J Comput Assist Tomogr 39(4):607-612. https://doi.org/10.1097/rct.0000000000000239

34. Martini I, Polici M, Zerunian M, Panzuto F, Rinzivillo M, Landolfi F, Magi L, Caruso D, Eid M, Annibale B, Laghi A, Iannicelli E (2020) CT texture analysis of liver metastases in PNETs versus NPNETs: correlation with histopathological findings. Eur J Radiol 124:108812. https://doi.org/10.1016/j.ejrad.2020.108812

35. Win T, Miles KA, Janes SM, Ganeshan B, Shastry M, Endozo R, Meagher M, Shortman RI, Wan S, Kayani I, Ell PJ, Groves AM (2013) Tumor heterogeneity and permeability as measured on the CT component of PET/CT predict survival in patients with non-small cell lung cancer. Clin Cancer Res 19(13):3591-3599. https://doi.org/10.1158/1078-0432.CCR-12-1307

36. Hayano K, Kulkarni NM, Duda DG, Heist RS, Sahani DV (2016) Exploration of imaging biomarkers for predicting survival of patients with advanced non-small cell lung cancer treated with antiangiogenic chemotherapy. AJR Am J Roentgenol 206(5):987993. https://doi.org/10.2214/AJR.15.15528

37. Ravanelli M, Agazzi GM, Ganeshan B, Roca E, Tononcelli E, Bettoni V, Caprioli A, Borghesi A, Berruti A, Maroldi R, Farina D (2018) CT texture analysis as predictive factor in metastatic lung adenocarcinoma treated with tyrosine kinase inhibitors (TKIs). Eur J Radiol 109:130-135. https://doi.org/10.1016/j.ejrad.2018. 10.016
38. Ravanelli M, Agazzi GM, Milanese G, Roca E, Silva M, Tiseo M, Rondi P, Baggi A, Ganeshan B, Muri M, Panni S, Botti C, Sverzellati N, Maroldi R, Berruti A, Farina D (2019) Prognostic and predictive value of histogram analysis in patients with non-small cell lung cancer refractory to platinum treated by nivolumab: a multicentre retrospective study. Eur J Radiol 118:251-256. https:// doi.org/10.1016/j.ejrad.2019.07.019

39. Mattonen SA, Palma DA, Haasbeek CJ, Senan S, Ward AD (2013) Distinguishing radiation fibrosis from tumour recurrence after stereotactic ablative radiotherapy (SABR) for lung cancer: a quantitative analysis of CT density changes. Acta Oncol 52(5):910-918. https://doi.org/10.3109/0284186X.2012.731525

40. Cohen JG, Reymond E, Medici M, Lederlin M, Lantuejoul S, Laurent F, Toffart AC, Moreau-Gaudry A, Jankowski A, Ferretti GR (2018) CT-texture analysis of subsolid nodules for differentiating invasive from in-situ and minimally invasive lung adenocarcinoma subtypes. Diagn Interv Imaging 99(5):291-299. https://doi.org/10. 1016/j.diii.2017.12.013

41. Fraioli F, Lyasheva M, Porter JC, Bomanji J, Shortman RI, Endozo R, Wan S, Bertoletti L, Machado M, Ganeshan B, Win T, Groves AM (2019) Synergistic application of pulmonary (18) F-FDG PET/HRCT and computer-based CT analysis with conventional severity measures to refine current risk stratification in idiopathic pulmonary fibrosis (IPF). Eur J Nucl Med Mol Imaging 46(10):2023-2031. https://doi.org/10.1007/s00259-019-04386-5

42. Ganeshan B, Miles KA, Young RC, Chatwin CR (2008) Threedimensional selective-scale texture analysis of computed tomography pulmonary angiograms. Invest Radiol 43(6):382-394. https:// doi.org/10.1097/RLI.0b013e3181690091

43. Kloth C, Blum AC, Thaiss WM, Preibsch H, Ditt H, Grimmer R, Fritz J, Nikolaou K, Bosmuller H, Horger M (2017) Differences in texture analysis parameters between active alveolitis and lung fibrosis in chest CT of patients with systemic sclerosis: a feasibility study. Acad Radiol 24(12):1596-1603. https://doi.org/10. 1016/j.acra.2017.07.002

44. Kloth C, Thaiss WM, Beck R, Haap M, Fritz J, Beer M, Horger M (2019) Potential role of CT-textural features for differentiation between viral interstitial pneumonias, pneumocystis jirovecii pneumonia and diffuse alveolar hemorrhage in early stages of disease: a proof of principle. BMC Med Imaging 19(1):39. https:// doi.org/10.1186/s12880-019-0338-0

45. Yao J, Dwyer A, Summers RM, Mollura DJ (2011) Computeraided diagnosis of pulmonary infections using texture analysis and support vector machine classification. Acad Radiol 18(3):306314. https://doi.org/10.1016/j.acra.2010.11.013

46. Dohan A, Gallix B, Guiu B, Le Malicot K, Reinhold C, Soyer P, Bennouna J, Ghiringhelli F, Barbier E, Boige V, Taieb J, Bouche O, Francois E, Phelip JM, Borel C, Faroux R, Seitz JF, Jacquot S, Ben Abdelghani M, Khemissa-Akouz F, Genet D, Jouve JL, Rinaldi Y, Desseigne F, Texereau P, Suc E, Lepage C, Aparicio T, Hoeffel C, Investigators P, Investigators P (2020) Early evaluation using a radiomic signature of unresectable hepatic metastases to predict outcome in patients with colorectal cancer treated with FOLFIRI and bevacizumab. Gut 69(3):531-539. https://doi.org/ 10.1136/gutjnl-2018-316407

47. Miles KA, Ganeshan B, Griffiths MR, Young RC, Chatwin CR (2009) Colorectal cancer: texture analysis of portal phase hepatic CT images as a potential marker of survival. Radiology 250(2):444-452. https://doi.org/10.1148/radiol.2502071879

48. Yasaka K, Akai H, Mackin D, Court L, Moros E, Ohtomo K, Kiryu S (2017) Precision of quantitative computed tomography texture analysis using image filtering: a phantom study for scanner variability. Medicine 96(21):e6993. https://doi.org/10.1097/MD. 0000000000006993

49. Ng F, Kozarski R, Ganeshan B, Goh V (2013) Assessment of tumor heterogeneity by $\mathrm{CT}$ texture analysis: can the largest 
cross-sectional area be used as an alternative to whole tumor analysis? Eur J Radiol 82(2):342-348. https://doi.org/10.1016/j. ejrad.2012.10.023
Publisher's Note Springer Nature remains neutral with regard to jurisdictional claims in published maps and institutional affiliations.

\section{Authors and Affiliations}

\section{Damiano Caruso ${ }^{1}$. Francesco Pucciarelli ${ }^{1}$ - Marta Zerunian ${ }^{1} \cdot$ Balaji Ganeshan ${ }^{2}$. Domenico De Santis ${ }^{1}$. Michela Polici ${ }^{1}$. Carlotta Rucci ${ }^{1}$. Tiziano Polidori ${ }^{1}$. Gisella Guido ${ }^{1}$ - Benedetta Bracci ${ }^{1}$. Antonella Benvenga ${ }^{1}$. Luca Barbato ${ }^{1}$. Andrea Laghi ${ }^{1}$ (iD)}

Damiano Caruso

damiano.caruso@uniroma1.it

Francesco Pucciarelli

francesco.pucciarelli@uniroma1.it

Marta Zerunian

marta.zerunian@uniroma1.it

Balaji Ganeshan

b.ganeshan@ucl.ac.uk

Domenico De Santis

domenico.desantis@hotmail.it

Michela Polici

michela.polici@uniroma1.it

Carlotta Rucci

carlotta.rucci@uniroma1.it

Tiziano Polidori

tiziano.polidori@uniroma1.it
Gisella Guido

gisella.guido@uniroma1.it

Benedetta Bracci

benedetta.bracci@uniroma1.it

Antonella Benvenga

geltrude.a@gmail.com

Luca Barbato

lucabarbatotsrm@gmail.com

Department of Medical-Surgical Sciences and Translational Medicine, Sapienza University of Rome - Sant'Andrea University Hospital, Via di Grottarossa, 1035-1039, 00189 Rome, Italy

2 Institute of Nuclear Medicine, University College London Hospitals NHS Trust, London, UK 